\title{
Different influences of physiological and medicamentous hyperprolactinemia on calcium metabolism in rats - experimental study
}

\author{
Danijela Radojkovic, Milica Pesic, Slobodan Antic, Sasa Radenkovic, \\ Marija Vukelic, Tatjana Jevtovic Stoimenov \\ Medical Faculty, University Nis, Serbia \\ Clinic for endocrinology, diabetes and metabolic disorders, Clinical Center Nis, Serbia
}

\section{Introduction}

The mechanism by which hyperprolactinemia in pregnancy leads to mild and reversible changes in maternal skeletal system and medicamentous hyperprolactinemia causes more detrimental effects, is not completely clarified.

The aim of the study

We conducted the experimental study to compare prolactin receptor gene (Prlr) expression in the duodenum, vertebra and kidney, during physiological and medicamentous hyperprolactinemia which could influence calcium homeostasis.

Experimental design

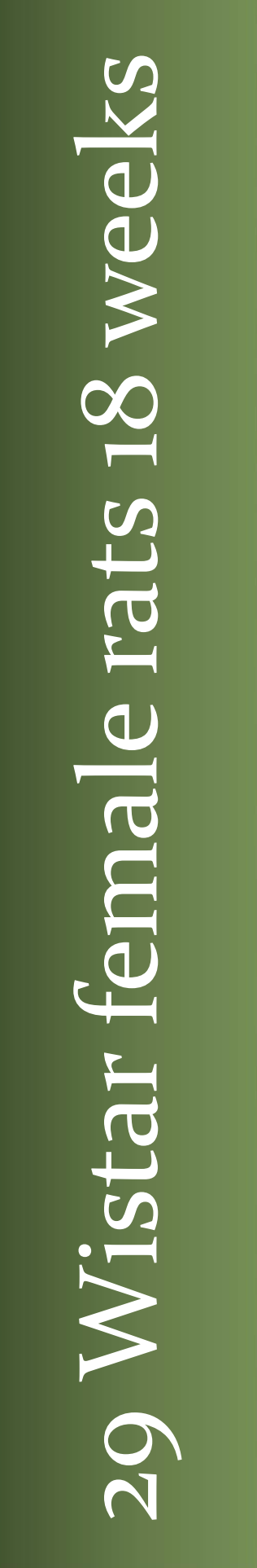

Group P: 9 rats, 3 week pregnant (physiological hyperprolactinemia)

Experimental rats with hyperprolactinemia

Experimental rats with normal prolactin
Group M: 10 rats, that were intramuscular administrated Sulpirid (10 mg/kg) twice daily for 3 weeks (medicamentous hyperprolactinemia)

Group C: 10 rats, age matched nulliparous (control group)

Laboratory results

\begin{tabular}{|c|c|c|c|}
\hline & P-group & M-group & C-group \\
\hline $\begin{array}{c}\text { PRL }(\mathrm{pg} / \mathrm{mL}) \\
\mathrm{X} \pm \mathrm{SD}\end{array}$ & $181,80 \pm 29,65^{a}$ & $182,03 \pm 57,80^{a}$ & $105,38 \pm 28,34$ \\
\hline $\begin{array}{c}\mathrm{s}-\mathrm{Ca}++(\mathrm{mmol} / \mathrm{L}) \\
\mathrm{X} \pm \mathrm{SD}\end{array}$ & $0,5 \pm 0,2^{a}$ & $1,15 \pm 0,04^{\mathrm{a}}$ & $1,12 \pm 0,04$ \\
\hline $\begin{array}{c}\mathrm{s}-\mathrm{P}(\mathrm{mmol} / \mathrm{L}) \\
\mathrm{X} \pm \mathrm{SD}\end{array}$ & $2,42 \pm 0,46^{c}$ & $2,14 \pm 0,48$ & $2,05 \pm 0,19$ \\
\hline $\begin{array}{c}\mathrm{u}-\mathrm{Ca}(\mathrm{mmol} / \mathbf{2 4 h}) \\
\mathrm{X} \pm \mathrm{SD}\end{array}$ & $3,90 \pm 0,46^{a}$ & $4,31 \pm 1,111^{b}$ & $3,05 \pm 0,58$ \\
\hline $\begin{array}{c}\mathrm{u}-\mathrm{P}(\mathrm{mmol} / \mathbf{2 4 h}) \\
\mathrm{X} \pm \mathrm{SD}\end{array}$ & $141,15 \pm 20,65^{a}$ & $50,58 \pm 9,77$ & $45,54 \pm 7,99$ \\
\hline $\begin{array}{c}\text { TP1NP }(\mathrm{pg} / \mathrm{mL}) \\
\mathrm{X} \pm \mathrm{SD}\end{array}$ & $489,22 \pm 46,77^{a}$ & $309,60 \pm 36,74^{c}$ & $361,90 \pm 53,01$ \\
\hline
\end{tabular}

Relative expression of mRNA Prlr in duodenum

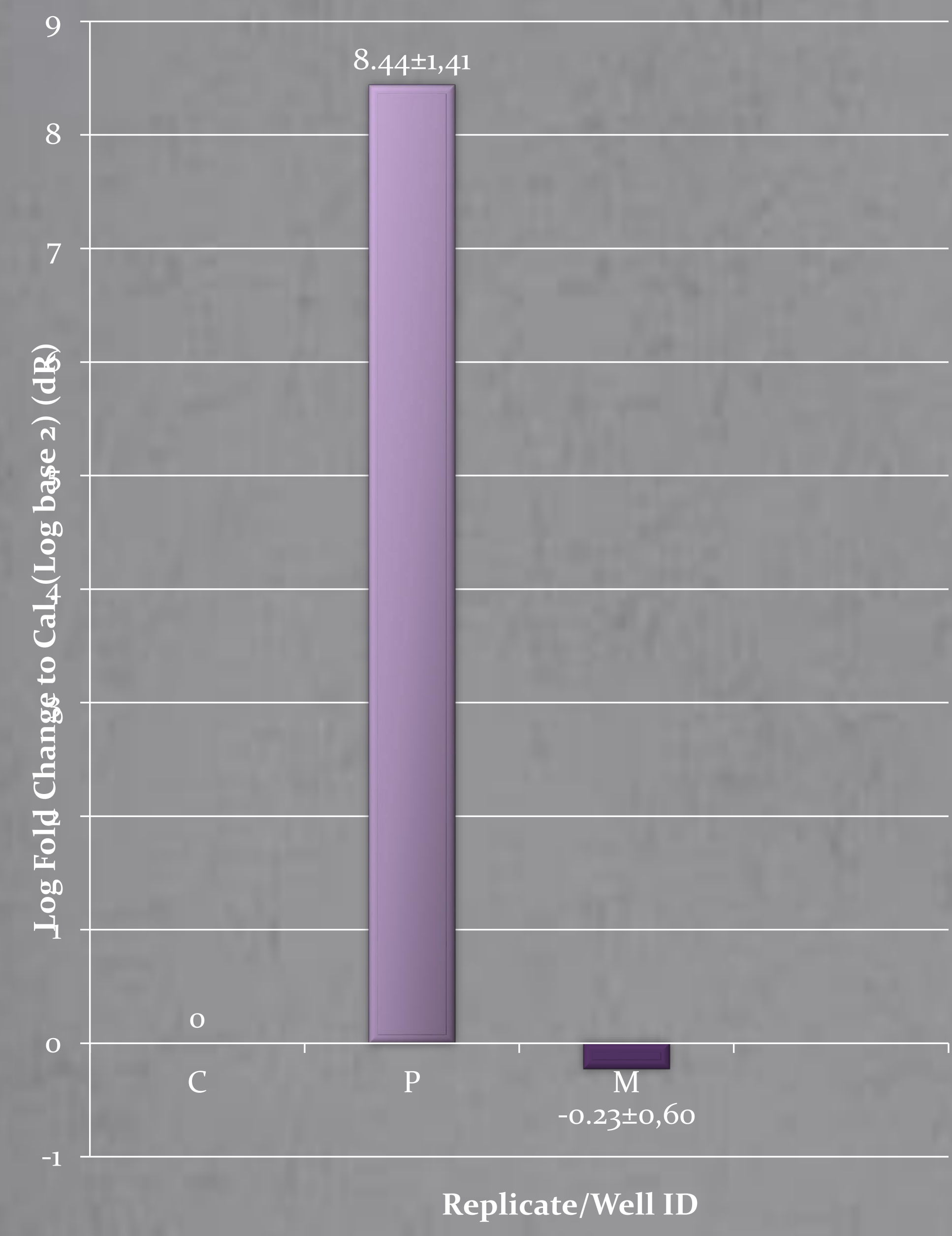

$\log _{2}(\mathrm{P} / \mathrm{C})$ vs $(\mathrm{M} / \mathrm{C}) \mathrm{p}<0,001$
Relative expression of mRNA Prlr in vertebra

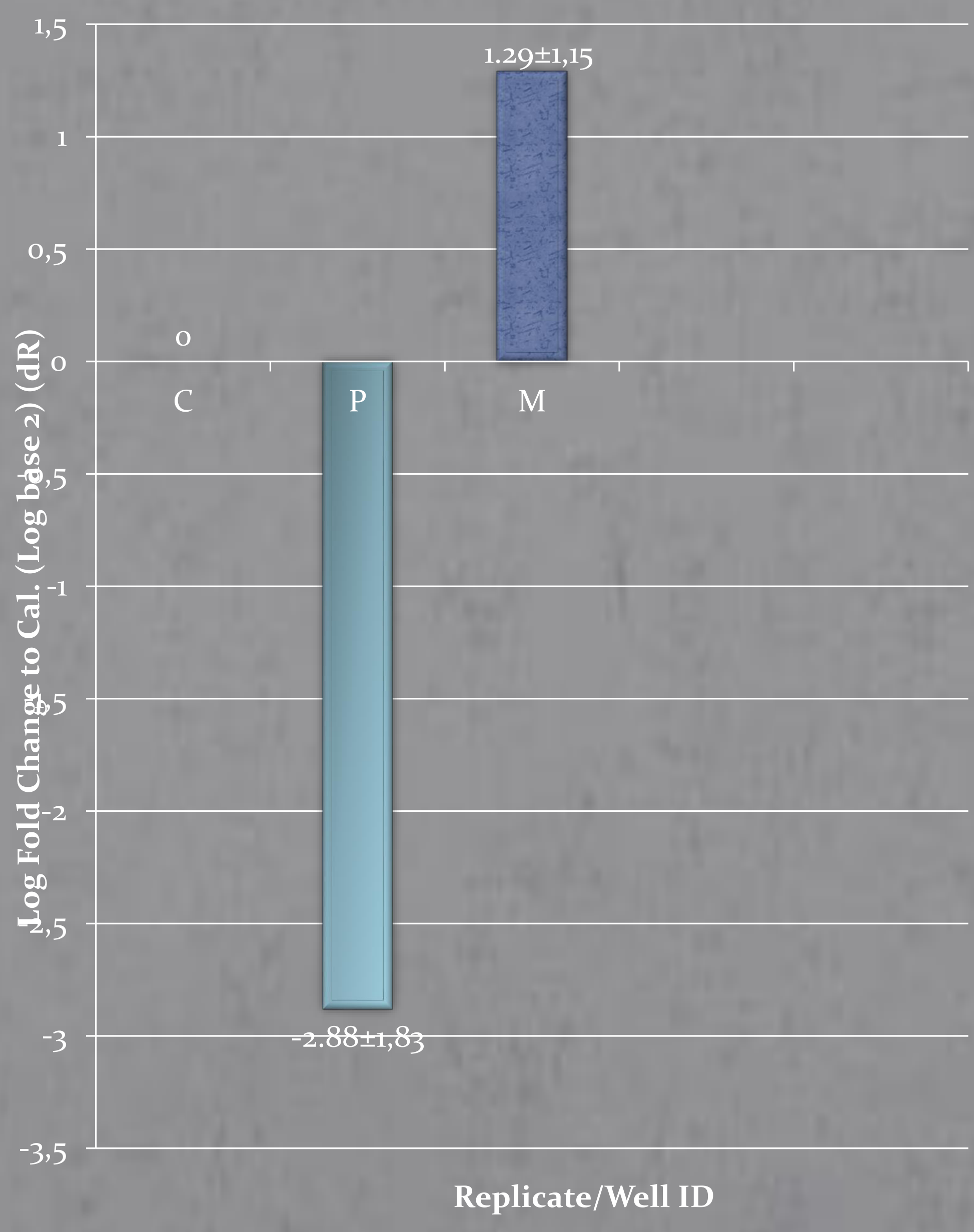

$\log _{2}(\mathrm{P} / \mathrm{C})$ vs $(\mathrm{M} / \mathrm{C}) \mathrm{p}<0,001$
Relative expression of mRNA Prlr in kidney

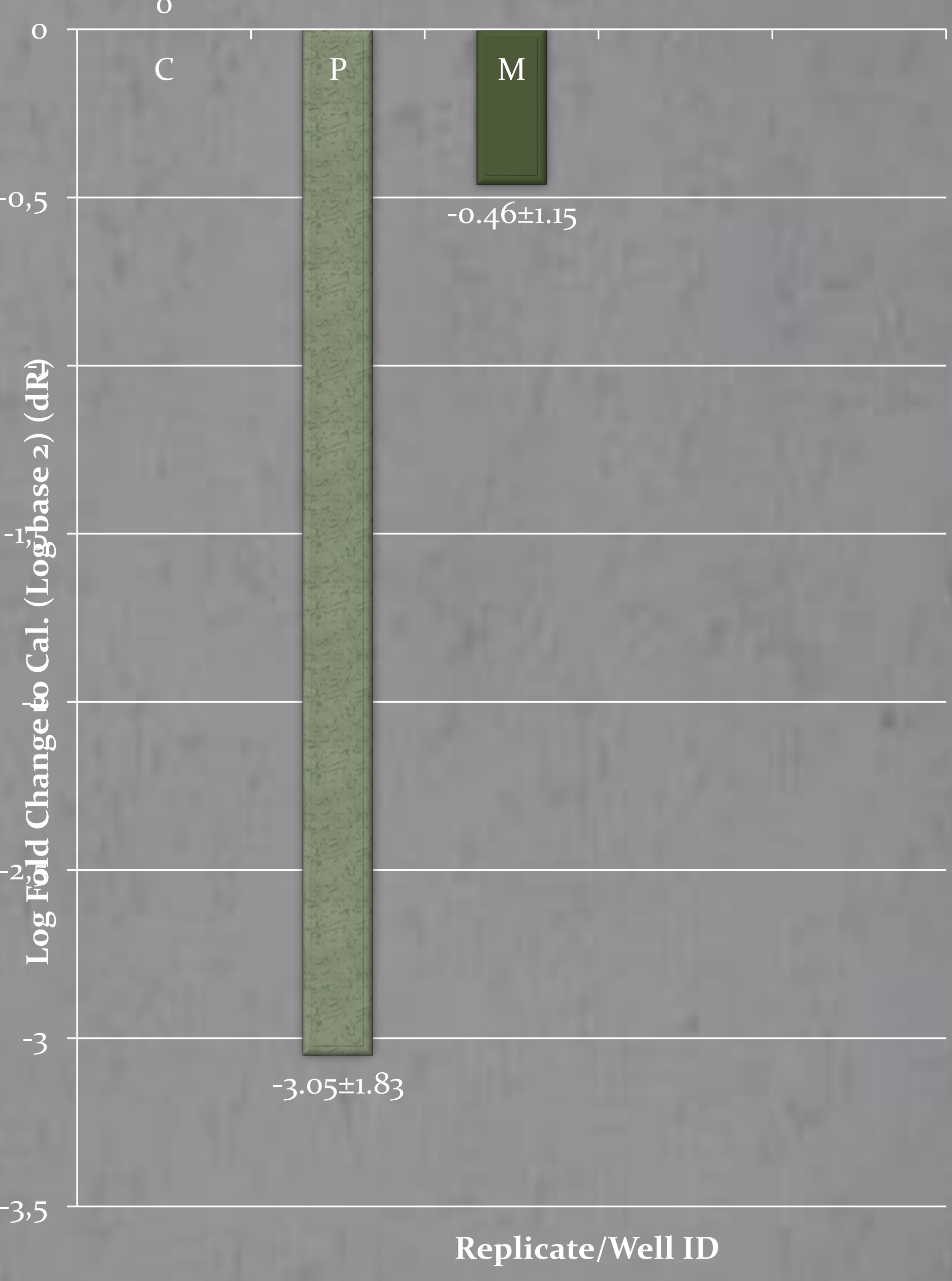

$\log _{2}(\mathrm{P} / \mathrm{C})$ vs $(\mathrm{M} / \mathrm{C}) \mathrm{p}<0, \mathrm{ol}$

\section{Conclusion}

In medicamentous hyperprolactinemia, down-regulation of Prlr gene expression in duodenum could be underlying reason for diminished intestinal calcium absorption. Increased calciumuresis could be partly due to down-regulated Prlr gene expression in the kidney. In order to

maintain calcium homeostasis, since intestinal absorption is compromised and loosing via kidney elevated, prolactin will rapidly take calcium from skeletal system, thank to increased Prlr gene expression in the vertebra, leading to more harmful effect on bone metabolism compering to physiological hyperprolactinemia. 